\title{
FENOMENOLOGÍA DEL SENTIDO DE LA VIDA HUMANA EN LOS ÚLTIMOS ENSAYOS DE JAN PATOČKA*
}

\author{
Ivan Chvatik \\ Patočka-Archiv, Praga, República Checa \\ chvatik@cts.cuni.cz
}

\begin{abstract}
Resumen
Jan Patočka (1907-1977), filósofo checo de renombre mundial, escribió su tesis de habilitación con E. Husserl en Friburgo, lugar en donde también se familiarizó con la obra de M. Heidegger. En su propia obra, Patočka trató de resolver el conflicto filosófico entre sus diferentes conceptos de fenomenología. El intento de añadir una dimensión histórica a la noción de Lebenswelt y al concepto de fenomenología como tal le llevó finalmente a formular una filosofía de la historia fenomenológica. En su último artículo, el cual es el tema principal de mi conferencia, Patočka esboza una "historia de la filosofía del significado de la vida humana, empezando en Kant" y expone su propio concepto del significado de la historia, influenciado por motivos heideggerianos. Yo expongo aquí una interpretación concisa de su idea y adopto una postura crítica con respecto a ella.
\end{abstract}

\begin{abstract}
Jan Patočka (1907-1977), Czech philosopher of world importance, wrote his habilitation script with Edmund Husserl in Freiburg, where he also became acquainted with the work of Martin Heidegger. In his own work, Patocka tried to resolve the philosophical conflict between their various concepts of phenomenology. The attempt to add a historical dimension to the notion of Lebenswelt and to the concept of phenomenon as such led him ultimately to formulate a phenomenological philosophy of history. In his last essay, which is the main subject of my lecture, $\mathrm{Pa}$ točka sketches out a "history of the philosophy of the meaning of human life, beginning with Kant" and sets forth his own concept of the meaning of history, influenced by Heideggerian motifs. I present a concise interpretation of his idea and take a critical position towards it.
\end{abstract}

El horrible atentado terrorista del 11 de marzo confirmó de modo perverso la actualidad del tema de este ensayo. Es evidente que el mundo actual está determinado por el conflicto, aunque por otra parte nosotros sea-

\footnotetext{
Ponencia presentada en el VII Congreso Internacional de Fenomenología, "Interculturalidad y Conflicto", organizado por la Sociedad Española de Fenomenología, en la Universidad de Salamanca (España), los días 28-30 de abril de 2004.
} 
mos testigos de un desarrollo nunca visto de contactos formales e informales entre hombres, en todo el globo. Tenemos para ello una expresión que, junto a su contenido indudablemente positivo, va acompañado fuertemente de connotaciones negativas: la globalización.

Cuando hace años, en noviembre de 2002, con ocasión del noventa y cinco cumpleaños del filósofo checo Jan Patočka, por iniciativa de Lester Embree organizamos en Praga un congreso internacional a partir del cual fue fundada la Organización mundial de Organizaciones Fenomenológicas (OPO), en mi contribución sobre la comprensión fenomenológica de la historia defendida por Patočka intenté hacer comprender que, junto a otros, era, precisamente, un pensador del conflicto. A ello le estimuló no sólo su experiencia de vida intelectual o, mejor dicho, la experiencia de un hombre espiritual y pensador del siglo XX - siglo que fue ante todo, a escala mundial, un siglo de guerras y de opresión totalitaria de los pueblos-, sino_también su experiencia filosófica. Al comienzo de su trayectoria filosófica pasó 1933 en Freiburg con una ayuda de la Fundación Humboldt, donde, bajo la dirección del emérito Husserl, preparó su habilitación y asistió oficialmente a las lecciones del entonces rector de la Universidad, Martin Heidegger. Con ayuda de Eugen Fink, asistente de Husserl, tenía Patočka, entonces, la posibilidad, de penetrar en la en ese momento pública disputa entre las concepciones de la fenomenología de Husserl y Heidegger. Patočka se esforzó luego, a lo largo de toda su vida, en orientarse en esa disputa filosófica y en superarla a su modo. No creo exagerar cuando digo que precisamente ese esfuerzo le motivó a lo largo de todo su trabajo filosófico y le condujo a resultados que no podemos desatender por más tiempo.

El estudio de la fenomenología de Husserl y Heidegger condujo a Patočka a la convicción de que los conflictos y las crisis - tanto en la vida de los individuos como también en la historia- siempre de algún modo proceden del conflicto que siempre está presente en la profundidad del ser. En un sentido profundo el ser es, en sí mismo, conflictual, y este conflicto acontece justamente en el aparecer en el ámbito más primitivo que estudia la fenomenología, en el ámbito del fenómeno. El aparecer de aquello que es depende de nuestra comprensión a cuyo través nos aparece el ente; depende 
de cómo aparece el ser. Pero este comprender se oculta, a la vez, en el aparecer $y$, precisamente en lo que se nos muestra, en el ente mismo que se muestra a sí mismo. Y Patočka ve la estructura histórica del fenómeno, tal como se conformó en la segunda mitad del siglo $\mathrm{XX}$, como objetivamente dramática:

"Esta ocultación no es sólo un cegamiento, un blindaje; es un conflicto, una lucha, algo que tiene lugar en el mostrar-se mismo. ¿En qué consiste el conflicto? En que la vida, que es una vida en claridad, se transforma en estas cosas claras, en que el trascendedor se pierde en favor de lo trascendido y, en consecuencia, la vida se deniega a sí misma en su vitalidad. Esto aparece luego no sólo como peligro, sino como más -en ello estriba justamente la inhumanidad, la dureza y la brutalidad de la vida frente a la vida". (PD III, $394^{1}$ )

Incluso si aquí es clara la influencia de Heidegger, vemos que Patočka va más allá. No habla más del mero "peligro", sino justamente del conflicto, y él quiere prepararse con Heidegger no sólo respecto al futuro "favor del ser" por medio del pensar y del arte, sino que quiere finalmente actuar históricamente. Comprende la historia de la fenomenología en el seminario, entonces, en la siguiente afirmación:

\begin{abstract}
"Del esfuerzo de Husserl por una solución de la crisis a través del saber nos salvamos por el esfuerzo de Heidegger por salvar la crisis a través del arte, arribado a la pregunta de si no se tiene que hacer frente al peligro en lugar de sólo esperarlo. Y, a la vez, [...] si no se debería conceptuar ese peligro no sólo como un mero velo, sino como un conflicto que nos destina a la lucha y en el que somos también consumidos". (PD III, 393)
\end{abstract}

Poco después de que hubiese dicho estas palabras, Patočka se convirtió en uno de los tres primeros portavoces del movimiento de derechos humanos Carta 77, y en marzo de 1977 pagó con su vida en el conflicto de este movimiento en el poder político totalitario.

Ya en su escrito de habilitación sobre El mundo natural como problema filosófico (1936) proyecta Patočka su investigación sobre el mundo natural

1 En adelante, se citará por la edición checa de Patočka Gesammelten Schriften (Sebrané spisy), vol. 3 (Péče o duši III, editores: I. Chvatík u. P. Kouba), Praha, 2002. En adelante este texto se citará como PD III. 
-que, de acuerdo con el programa husserliano de la fenomenología, debe proporcionar "una orientación en la prehistoria ideal del pensamiento teorético"- como una investigación histórica. Ya aquí ve que la tarea de "esclarecer las estructuras del aparecer en su originariedad", "de alcanzar la vida concreta en el mundo", no se deja extraer sin "reflexiones sobre la historia humana", sin una cierta filosofía fenomenológica de la historia. A este tema consagró más o menos toda su vida. Es relativamente conocida una colección de ensayos de Patočka, que aparecen a partir de los años 1974-1975, bajo el título Ensayos heréticos sobre filosofía de la historia, en los que resume de forma especialmente comprimida su investigación a lo largo de su vida. En qué estrecha conexión plantea la temática del aparecer, de la fenomenologización, con la de la historia, dice él en el primer ensayo:

"Sin embargo, la apertura del mundo bajo todas sus formas es siempre histórica, según el mostrarse de los fenómenos y la acción de los hombres, que conservan y transmiten. La apertura transcurre como acontecimiento en la vida de los individuos, pero afecta a todos a través de la tradición". (KE, 32²)

Y, en uno de los esbozos preparatorios para este ensayo, añade:

"Pero se trata de la pregunta de si la historicidad es un fenómeno o un momento fenomenal $-y$ que sea un momento fundamental e importante-, o si el fenómeno es el momento fundamental de la historia, algo que funda la historia y sin lo cual no es pensable. De este modo, el fenómeno sería en só no sólo algo histórico, sino que la historia sería necesariamente una historia fenomenológica". (PD III, 453)

El conceptuar la historia como historia de la fenomenalización y el conceptuar la estructura de la fenomenalización como formación histórica de un conflicto en el ser no sólo conduce a Patočka a comprender su investigación histórico-filosófica ciertamente como una fenomenología del sentido de la vida humana o, en su caso, como una filosofía histórica del sentido, sino también a que se plantee expresamente la pregunta por el sentido de la vida humana o, en su caso, de la historia, y a intentar responder a ello. ¿Tie-

2 Aquí y en las siguientes citas: J. Patočka, Ketzerische Essais zur Philosophie der Geschichte (editores: K. Nellen / J. Němec), Stuttgart, 1984. En adelante este texto se citará como KE. 
ne un sentido la historia? Es el título del tercero de los Ensayos heréticos. ¿Aspira la historia a alguna meta, se puede descubrir en sus enlaces y vínculos algún contenido armonizador? Tal pregunta se plantea el hombre, naturalmente, en una situación en la que se ha perdido el sentido. En esta situación de indigencia de un sentido abarcativo está la humanidad hace ya mucho tiempo. Desde los tiempos de Nietzsche, incluso antes de él, hay para esta situación una caracterización: nihilismo.

Pero en sus ensayos sobre filosofía de la historia muestra Patočka que la "experiencia de la pérdida del sentido" es ya mucho más antigua, que la "conmoción de la sensibilidad" está justamente al comienzo de la época que llamamos histórica, de modo que no sólo así está como producto adjunto al comienzo, sino que el descubrimiento de la interrogabilidad de la posición humana en el mundo mismo es ese comienzo. La historia comienza, según Patočka, con la comprensibilidad del mundo; como nos la transmite el mito, en sí se derrumba. Este mundo es comprensible porque "hay poderes, lo demoníaco, dioses, que están sobre el hombre, lo dominan y deciden sobre él" (KE, 35). En tal mundo hay mucho misterio - se podría decir que casi todo lo es-, y, sin embargo, ninguna interrogabilidad, pues "las preguntas plantean ya una posible liberación, una distancia respecto a lo que ya somos y en lo que nos encontramos" (PD III, 28). La historia comienza, según Patočka, allí donde acontece una "liberación"; el hombre comienza a plantearse expresamente preguntas que no eran necesarias en el mito.

El acento lo tenemos que poner en esta consideración sobre la palabra "expresamente". Se podría argüir justamente que una distancia frente a nuestro entorno inmediato, una transgresión existencial de aquello en lo que nos encontramos inmediatamente, una orientación al futuro y al pasado, a lo no presente y al mundo de la fantasía, caracterizó a los hombres como tales ya mucho antes, y que esa distancia equivale significativamente a que el hombre hable, comunique y se entienda en el mundo con ayuda del lenguaje. Pero tal comprensión puede ser $-y$, como dice Heidegger en Ser $y$ tiempo, será siempre ante todo y en general- una comprensión aproblemáticamente evidente, donde la respuesta esté dada ya antes de que se llegue a una pregunta. El mito es, en este sentido, una articulación de la plenitud 
de sentido que el hombre mama como la leche materna, un relato que tiene preparadas respuestas para todas las posibles preguntas antes de que puedan emerger como preguntas. Este sentido lo acepta el hombre, por tanto, ya desde fuera, y Patočka lo denomina el sentido aceptado. Esto no significa, con toda claridad, que no aparezca en el tiempo mítico ninguna pregunta importante. Pero serían respondidas en el estilo de la narración mítica y nuevamente incorporadas como tales a la tradición. Con la formulación expresa de una pregunta piensa Patočka la situación en que un individuo concreto - para su propia sorpresa- plantea una pregunta a la que la narración mítica no le ofrece una respuesta aceptable ya de entrada, como era costumbre, y donde luego es obligado a hacerse consciente expresamente de la maravilla de esta situación, para formular expresamente una pregunta a fin de articular la sorpresa como suya propia y sostenerla como tal, por tanto, por ejemplo, como miedo ante lo demoníaco, que estaba acostumbrado a vencer permanentemente desde el mito, sin que ello le hubiese conducido a una individualización.

Tan pronto como se llega a semejante articulación y el hombre, al que ello le ocurre, no deja hundirse ese acontecimiento -¿dónde, propiamente?, ¿en la subconsciencia? ¿o quizás justamente en la narración mítica? ¿en una respuesta que, sin embargo, se da cada pregunta desapacible, sorprendente, y que después se torna tradicional en el mito como una respuesta preparada de antemano?-, tan pronto como no deja hundirse esa pregunta, sino que le echa el guante, se convertirá en otro diferente del que era antes. Se producirá, entonces, aquella distancia frente al mundo circundante que siempre estaba en juego, claramente visible, en el lenguaje como lenguaje. La luz en la que se ha de ver esa distancia arroja la pregunta misma, pero lo fundamental que el hombre ve en esta luz es el hecho de que no tiene respuesta alguna a su pregunta, que el guante fue lanzado a un oscuro Enfrente para el que no es fácil estar preparado. Pero quien echa el guante es libre y está resuelto a defender su libertad.

Aproximadamente en este sentido habla Patočka de la liberación del mito que describe el hundimiento del sentido aceptado y el comienzo de una búsqueda explícita de un sentido al que el hombre no acepta obligado desde 
fuera, sino al que libremente encuentra como respuesta a su pregunta; un sentido, por tanto, al que podría, expresamente, asumir en su responsabilidad personal.

Los primeros pasos en el camino de la realización de este programa los ve Patočka en la Grecia antigua, en la que surgen las primeras escuelas filosóficas en las ciudades-estado independientes, y el planteamiento expreso de preguntas comienza a ser vinculado con personas concretas, con nombre. Habla Patočka del surgimiento conjunto de política y filosofía. Los ciudadanos libres de estos estados consiguieron su libertad en el combate y llegaron a que podrían mantener el orden duramente, con medios políticos, sobre el fundamento de un recíproco respeto de las partes concurrentes. Quisieron apoyar con conocimiento verdadero sus puntos de vista sobre lo que es correcto y acerca de cómo decidir en situaciones problemáticas en las que hasta el momento el hilo conductor era irrenunciable, y fundamentar sus decisiones.

El vínculo de política y filosofía conduce, según Patočka, a la consecución de algunos grandes sistemas de metafísica. Patočka nombra a Platón, Demócrito y Aristóteles. El conocimiento definitivo del orden del Todo debía hacer posible alcanzar una ordenación humana.

"La filosofía busca precisamente en su forma de metafísica penetrar en el secreto de la fundamental interrogabilidad que era el punto de salida de aquella conmoción que hace emerger ante todo la filosofía - sin embargo sale al encuentro nuevamente en la forma del enigma de la pluralidad de los conceptos metafísicos y de los puntos de vista básicamente diferentes acerca del carácter de lo existente como tal". (KE, 91)

Esa pluralidad y los estados históricos del tiempo helenístico conducen a la skepsis y muestran que la filosofía que se apoya sobre el orden cósmico "no está en condiciones de dar al hombre un sentido superior de la vida, totalmente positivo", un sentido "sin aquella enigmaticidad que ha conducido la conmoción del sentido originariamente conformado" (KE, 93).

En esta situación entra el escena el cristianismo. San Pablo explica como locura la sabiduría de los filósofos antiguos que se esfuerzan en apoyar la plenitud de sentido sobre conceptos metafísicos, y ofrece a cada hombre un acceso directo a una plenitud de sentido que confirma el Dios trascen- 
dente. En virtud de que el cristianismo rechaza el distanciamiento filosófico de la interrogabilidad, rechaza sólo la solución filosófica, de ningún modo la pregunta. El Dios cristiano no entra en escena justamente como algo evidente. Dios es, por tanto, un nuevo tipo de respuesta a las viejas preguntas. Pero el Dios cristiano sólo da la respuesta al que quiere escucharla, a aquel que confía en él, y que tiene fe (PD III, 345ss).

La resolución cristiana de la interrogabilidad era muy eficaz. El abandonarse a Dios, sin embargo, finalmente enlazado con una intervención de los antiguos motivos metafísicos, condujo a la creación de la moderna civilización europea. En oposición al cristianismo nació una nueva racionalidad científica que, por una parte, condujo al surgimiento de la moderna ciencia matemática de la naturaleza y, por otra, al desarrollo de la teología racional. "Con esta teología racional sobrevivía en los hombres modernos la esperanza de que el recién descubierto método racional de una vez por todas, a priori y con certidumbre matemática, libre de toda premisa irracional [...] pudiera verificar las verdades fundamentales cristianas, los praeambula fidei" en la medida que en ella, sin embargo, directamente indagaba la Naturaleza creada por Dios $(T s c h P h, 213 f)^{3}$. Conocer la naturaleza con apodíctica certidumbre, como directamente por Dios creada, era un proyecto en el que la ciencia matemática de la Naturaleza y la teología racional estaban estrechamente vinculadas. La cumbre de este esfuerzo metafísico de los teólogos fueron las pruebas racionales de Dios ${ }^{4}$.

Sin embargo, gracias a que la teología aceptó ese carácter expresamente racional se hizo cada vez más claro que la tarea que se planteaba la enredaba en contradicciones que no se dejan solventar por la razón. El esfuerzo racional de fundamentar los artículos de fe con la convicción lógicomatemática, con la que comenzó a florecer la investigación científiconatural, condujo a la razón humana a que incluso comprendiera lo desesperado de su osadía. La explícita y exacta formulación de este estado de cosas

\footnotetext{
${ }^{3}$ Aquí y en lo que sigue: Die Sinnfrage in der Epoche des Nihilismus: Masaryk Dostojewski - Kant - Nietzsche - Heidegger, en L. Hagedorn (ed.), Tschechische Philosophen im 20. Jahrhundert, Stuttgart, 2002. En adelante este texto se citará como TschPh.

${ }^{4}$ En el Preludio de este ensayo, Patočka recomienda el libro de Dieter Henrich Der ontologische Gottesbeweis (Tübingen, 1960), en que el significado de la teología racional es minuciosamente examinado por la ciencia moderna.
} 
la consiguió Kant. El fin de su filosofía "crítica" era la liberación de la razón frente a las tareas que sobrepasan su posibilidad; así que ella, con fuerza completa, podría ganar el conocimiento científico en el ámbito que le era proporcionado a su capacidad de conocimiento. Justamente la prueba de esa proporción es, según Kant, la tarea de la metafísica. La seriedad y contundencia con que dispuso su propósito le aseguró para siempre un significativo lugar en la historia de la Filosofía. Puso no sólo las bases para la moderna teoría del conocimiento, como subrayan los neokantianos, sino que, como muestra Heidegger, también dio pasos decisivos en el ámbito de la ontología fundamental, que hasta hoy tienen influencia en toda la tradición filosófica.

En su último ensayo ${ }^{5}$ intentó Patočka, según sus propias palabras, "esbozar una filosofía histórica del sentido de la vida humana, comenzando con Kant" (TschPh, 296). Lo hizo, ante todo, para presentar al final una revisión de todos sus intentos y poder recapitular sus propios puntos de vista respecto a dicha problemática. Como vimos, esta cuestión había conseguido un significado fundamental ya en los Ensayos heréticos, en el curso de consideraciones sobre filosofía de la historia. Patočka vio, naturalmente, que el tema del sentido, tal como lo replanteó, no podía agotarlo en un ensayo relativamente breve. Por ello dice también en la conclusión: "Nuestra reflexión sirvió sólo como prolegómeno histórico de este problema y de sus fenómenos" (TschPh, 306). Porque no tuvo ninguna ocasión más para proseguir sus reflexiones tenemos que darnos por satisfechos con lo que dejó al morir. Intentamos proseguir sobre la base de sus análisis históricos, tal como se nos expone su posición, e interrogarla críticamente.

"En el estudio de la historia moderna del espíritu no somos frecuentemente conscientes del enorme significado que detenta para la Filosofía, como para la vida, la caída de esta teología racional a través de Kant" (TschPh, 213). Esta constatación se encuentra al comienzo de su ensayo, y llama la atención sobre que la investigación científica justamente gracias a que ella principalmente a través del servicio de Kant fue librada de las últi-

5 J. Patočka, Kolem Masarykovy filosofie náboženství, Praha, Samizdat, 1977; para la edición alemana véase arriba FN 3. En adelante este texto se citará como TschPh. 
mas cadenas con las que la ciencia de la Naturaleza estaba vinculada con la teología, se torna un ámbito en el que el conocer nada puede descubrir sino una inflexible causalidad de acontecer dominado mecánicamente. La nueva ciencia racional de la naturaleza se aislaba y, desde ella, se tornaba una "ciencia puramente materialista sin ninguna implicación de sentido" (idem). Con ello no ocurrirá nunca más que una y la misma forma de intuición pudiera garantizar tanto la libertad de la voluntad, la inmaterialidad e inmortalidad del alma, la existencia y la veracidad de Dios, así como la cognoscibilidad del mundo creado de la naturaleza. A partir de Kant ya no se puede conceptuar la naturaleza como un libro que escribió Dios para comunicarnos algo, en todo caso más de lo que ya sólo vemos, que justamente sus letras están ligadas a aquellas inflexibles leyes mecánicas. Comienza a hacerse claro que lo que está escrito en el libro no son propiamente letras que se vinculan a símbolos que indican más allá de ellos mismos, y que esto en general no es texto alguno, ni menos aún Dios. Dios, libertad e inmortalidad no se pueden encontrar en la ciencia de la Naturaleza.

El "enorme significado" de Kant del que habla Patočka consiste en que justamente lo que ya se sabía desde hacía mucho tiempo fue mostrado de un modo racional, incontrovertible. Hacía ya mucho despertó temores y miedo, pero no había sido demostrado a priori. La angustia fue disuelta por una destitución de la que hasta hoy no hemos encontrado la salida. De la actualidad de esta problemática testimonia asimismo cómo prosigue inadvertidamente en los actuales debates sobre el relativismo de los así llamados postmodernos -es igual si se los defiende o rechaza- o cómo es tratada de una forma que impide más bien que sea comprendida.

Ante todo, Kant mismo está obligado a enfrentarse de algún modo con la situación de la razón que él asienta de modo tan fundamental. Confiado a su racionalismo y a su comprensión para la construcción de sistemas científicos, desarrolla un cuidadoso intento de amplio alcance para poner a salvo la creencia por medio de su enlace con el ámbito de la moralidad. Sin embargo, no será la creencia en un Dios que solicita que cumplamos sus mandamientos, que nos prescribió con su omnipotencia, sino completamente al contrario: podemos reconocer como correctos sus mandamientos por noso- 
tros mismos, desde nuestra propia razón, justamente como algo a lo que nuestro entendimiento nos obliga por medio de que lo que tenemos, de que somos lo que somos, justamente seres racionales. El factum de la razón nos autoriza a tenernos por seres libres. Pero esta autonomía racional que expresa el imperativo categórico es en sí misma, justamente gracias a su pura racionalidad, desligada de todas las posibles condiciones empíricas de nuestra vida, una racionalidad completamente formal, abstracta y, por así decirlo, sin sentimiento. Es en sí misma incondicionada, y la voluntad moral que rige con su imperativo puede realizar libremente su acción moral en todas las circunstancias en el mundo empírico. En esta perspectiva es suficiente en sí misma: se basta a sí misma, no necesita nada más para su propia realización. En aplicación de una terminología que no es, naturalmente, la de kant, podríamos decir que semejante actuar tiene un sentido en sí mismo, o justamente que es el sentido, y precisamente de modo absoluto, sin que el hombre tuviera que percatarse de lo que produce junto a sí o fuera de sí. Aquello de lo que abstrae propiamente este actuar es justamente de aquello en lo que se realiza, justamente la relacionalidad en el acontecer empírico temporal. Pero tan pronto como salimos fuera de la formal absolutez del imperativo y tomamos nuevamente en consideración el mundo empírico, vemos que la consecución del bien supremo a través de una acción moral no puede valer en el ámbito empírico de la Naturaleza, el único en que actuemos.

Con ello se muestra el destacado e inquietante hecho de que la acción moral, sobre la base de su interior formal plenitud de sentido, podría carecer de aquel sentido desde el punto de vista del conseguir un fin. A la vista de este factum - que conecta con la contradicción que ofrece la la realidad empírica al actuar desde la libertad, tan pronto se trata de alcanzar el bien- y en la conciencia de aquello de que la razón teórica puede conocer justamente este ámbito, pero no puede encontrar en ello principalmente ningún fin último, ni menos aún un fin que se dejara comparar a la obtención de un bien supremo, está obligada la razón práctica a postular a Dios como creador del mundo, como un garante para que este mundo sin fin desde el punto de vista teórico aspire objetivamente, con nuestra interven- 
ción, a un bien supremo. De nuevo está obligada a postular un alma inmortal con la que el ser que actúa moralmente bajo los límites de la vida terrena, en el punto de fuga de la eternidad, justamente a través de la participación en este bien supremo, como pago por su actuar moral, experimente la felicidad que corresponde necesariamente a los supremos bienes. Que exista un Dios moral y que el alma sea inmortal son, por tanto, postulados de la razón práctica que se tienen que creer, pero no conocimientos de la razón teórica que fuesen demostrables desde principios ciertos. Formulan exigencias a partir de una armonía que abovedaría las antinomias de naturaleza y moralidad. Aunque no son conocimientos racionales, es, sin embargo, algo muy racional, algo que la razón ofrece necesariamente como contenido de creencia, con lo que sería reconciliada la abstracta incondicionalidad del imperativo moral con la corporalidad empíricamente condicionada y mortal del hombre completo. La teología moral debe, por tanto, poner a salvo la creencia, a la que ella a la vez reconcilia con la razón, porque, sin embargo, la razón misma ha reclamado la creencia como algo necesario.

La problematicidad que Kant descubrió la asumen grandes poetas como Goethe y Schiller, pero, como dice Patočka, "la circunstancia de que Hegel y Schelling como sucesores y opositores de Kant renovaran una metafísica ontoteológica dificultó, en cierto modo, conceptuar que con Kant penetró en la metafísica de la eternidad un estilo nuevo que se orientaba al sentido del mundo y de la vida..." (TschPh, 215). A la vez llama la atención sobre que también Husserl, en su La crisis de las ciencias europeas (§ 4), no fue suficientemente consciente de opr qué propiamente el entusiasmo ilustrado por una racionalidad universal acabó en crisis. Escribe Patočka:

"El lector [de Husserl] tiene que ganar la impresión de que la separación, el conflicto de los diferentes sistemas (filosóficos) constituía el fundamento para la skepsis; sin embargo, el fundamento propio para ello no era su diferencia sino, por el contrario, la conmoción de aquello que vinculaba esos sistemas, justamente las pruebas racionales de Dios y, en especial, la cartesiana, prueba que se basa en el concepto de ens necessarium. El modo en que la realidad en curso de la moderna historia del espíritu fue eximida de su sentido es tan ampliamente diferente de como Husserl describe este proceso, porque la alternativa de Husserl entre naturalismo objetivista y trascendentalismo subjetivista, que constituye, según su exposición, el eje del moderno combate en torno al sentido del ser, deja completamente a un lado aquella dominante 
problemática metafísica que en realidad llenaba siglos enteros, mientras que la alternativa por él considerada sólo se presenta con la desaparición de esta problemática, es decir, con Kant. El papel de Kant en el moderno trascendentalismo, pero también el de Descartes que va a una con él, son en Husserl, en consecuencia, desfigurados". (TschPh, 216ss)

El intento racionalista de Kant en favor de una defensa de la creencia lo conceptúa Patočka, pues, como proyecto implícito de una metafísica del sentido de la vida humana en el marco del sentido total del universo: "sin sentido no es posible en general ninguna acción humana [...], por otra parte se derrumba sin un sentido absoluto y total cualquier donación de sentido" (TschPh, 222). Sólo el franco esfuerzo de Kant por dejar en su lugar el fructífero proyecto matemático-mecánico de Naturaleza, que sólo recibe un sentido de metas humanas relativas, no sin un sostén absoluto en la trascendentalidad de Dios, deja aparecer con toda su fuerza la pregunta por el sentido del mundo y de la vida. Hasta entonces no era necesaria. Esto significa claramente, a la vez, que la solución de Kant no se hace cargo del problema del sentido metafísicamente conceptuado. Pero persiste hasta hoy su formulación metafísica, que solicita para el proyecto "relativo" del sentido en las concretas situaciones humanas un sostén "absoluto".

Otra estación en el camino hacia una fenomenología histórica del sentido la sitúa Patočka en Dostoievski ${ }^{6}$, y muestra cómo la solución kantiana del problema del sentido se torna objeto de su ataque: "Si el fin del mundo y de la vida debe ser conectado al punto de vista de una armonía última a la que se dirigen finalmente los esfuerzos de la plenitud moral, entonces eso implica el reconocimiento de una disarmonía y del mal como un hecho" (TschPh, 225). A partir de la argumentación de Ivan Karamazov se desprende que la aceptación de los postulados no es absolutamente necesaria, sino condicionada a que nosotros queremos actuar y para ello esperamos un pago en forma de felicidad. Si nos decidimos por un tal sentido, entonces se ha de reconocer el mal, y se puede decir entonces: "hay sentido moral del mundo a este precio -si así algo como mérito moral debe existir, en-

\footnotetext{
${ }^{6}$ Para esto, Patočka cita el libro de Ja. E. Golosovker, Dostojewski i Kant, Moskva, 1963. Para una discusión estrictamente conceptual de la teología moral de Kant, ver Patočka, Brüdern Karamasow, II. vol. 5. Libro: das Kapitel Empörung.
} 
tonces son el sufrimiento y la injusticia necesarios. Pero, ¿es necesario que el mundo tenga un sentido moral?" (TschPh, 230). Patočka subraya esta pregunta y muestra que el argumento de Dostoievski contra el sentido moral del mundo discurre "análogamente a la argumentación kantiana contra la teología racional. Así como la oposición de Kant a la ontoteología toca a la imposibilidad de llenar de contenido el concepto de un ser necesario, del mismo modo basa Ivan su oposición a la teología moral sobre la imposibilidad de la prueba de que el fin moral del universo sea apodícticamente necesario" (idem). Ivan Karamazov no desecha la creencia en Dios, pero rechaza al Dios de los postulados morales. Porque conserva, sin embargo, una formulación metafísico-moral del problema del sentido, restan para él dos posibilidades: "o hay otro sentido, hasta ahora no conceptuado, o no hay en general sentido alguno y [...] 'todo está permitido' " (TschPh, 233). Al drama de la decisión entre estas dos alternativas está consagrada en lo esencial la obra de Dostoievski como un escéptico que vacila entre las citadas alternativas y que se parece mucho a lo "anónimo público" (das Man) de Heidegger, pero con la diferencia de que sabe de su decadencia nihilista, sufre infinitamente en ella, pero no puede quitársela de encima. Como "una de sus pregnantes descripciones [...] de una superación de la etapa del subsuelo" (TschPh, 238) considera Patočka el relato El sueño de un hombre ridículo. Ve en dicho relato un paralelo con la comprensión heideggeriana de un giro posible desde la caída cotidianeidad, pasando por la experiencia temerosa de la nadería de todo lo existente, hasta la auténtica "transformación interior que [...] permite descubrir el trasfondo del acontecer mentado como evidente y no perceptible" (EschPh, 247). Esta maravilla del ser que sólo se muestra después de que todos los fines y metas decaen como nadería, "esta maravilla sobre cuya base nosotros [...] estamos en medio del Ente, es una unificación, una apertura que se deja describir con la palabra amor" (idem). "Pero este amor no pertenece a las cosas ni a los contenidos del mundo, sino a la parte del ser inmortal" (TschPh, 249).

Patočka intenta comprender existencialmente la religión del amor que Dostoievski opone a la teología moral de Kant. "La armonía que empuja al fin moral del mundo a una distancia infinita" se produce aquí con un golpe 
(TschPh, 213). Aunque el mal no ha desaparecido del mundo y de la vida, aunque la gente es también más desgraciada y muere, conocieron la plenitud y se han reconciliado. El rechazo de un progresar infinito conduce al rechazo del arreglo de la culpa y de la venganza y, a la vez, a la aceptación de la culpa de todos por todo, lo que Patočka pone en paralelo con el "querer tener una conciencia" de Ser y tiempo. La tragedia y el sinsentido no desaparecen del mundo, pero son asuntos meramente relativos. También la muerte y la corrupción reciben aquí un sentido: sólo en el encuentro con nuestra finitud nos podemos abrir a aquella "no existente" fuente del sentido. Pero el sentido no se muestra "como recompensa por mérito, como retribución y compensación del padecer, sino como algo que tenemos que constituir por nosotros mismos, en lo que nos tenemos que prodigar" (TschPh, 261ss).

Naturalmente, Patočka no cree haber explicado de este modo la propia posición de Dostoievski. Por el contrario. Dice expresamente: "Dostoievski descubre así un nuevo continente de sentido hasta ahora desconocido, pero piensa que sólo ha encontrado un nuevo camino para un viejo continente. La teología cristiana habla del amor, y el hombre renacido de Dostoievski habla también del amor. Sin embargo, ¿se trata en ambos casos del mismo discurso?" (TschPh, 262).

En amplia medida de su estudio se dedica Patočka brevemente al fundador y primer presidente de la república checoslovaca, T. G. Masaryk. Masaryk era un discípulo de Brentano y un viejo amigo de Husserl. En su primera gran obra Der Selbstmord als sociale Masseerscheinung der modernen Civilisation, que apareció por primera vez en 1881, trabajó la idea de que las causas principales para la tendencia moderna al suicidio son la pérdida de la fe religiosa y el así llamado subjetivismo moderno. Patočka critica duramente la comprensión positivista-sociológica de la religión de Masarik también en las cuestiones de sentido que aquí nos interesan, y muestra que ello arrastra la mala comprensión de Masarik de Kant y Dostoievski.

Pero lo más importante es la delimitación crítica de Nietzsche, al que Patočka conceptúa como el anunciador del nihilismo que ve la crisis del hombre moderno en que toda la interpretación metafísica del mundo y de la 
vida - desde Platón hasta el cristianismo actual- intenta proyectar la "nostalgia por una realidad plena de sentido en un Afuera de este mundo [...] y trasladar todos los valores fuera de esta realidad en un ideal 'mundo verdadero'" (TschPh, 285). Pero en esta estimación ante la verdad, que pertenece igualmente a esos valores absolutos, el cristianismo mismo ha descubierto la mendicidad de su interpretación del mundo y se ha verificado como la fuente genuina del nihilismo. Para Patočka, Nietzsche es el enunciador de un "antropomorfismo que se convierte en principio metafísico" (TschPh, 286). Un hombre que combate la ilusión del trasmundo vence al nihilismo con una nueva posición positiva. Su meta es el desconsiderado sometimiento de los planetas. "Una animalidad creativa, pero bestialmente dura, rige al mundo" (TschPh, 287) ${ }^{7}$.

Con lo que propiamente no podría estar de acuerdo Patočka es con la idea de Nietzsche del "eterno retorno de lo mismo". Intenta conceptualizarlo como "refutación de la primera tesis de Kant y, con ello, de la doctrina de las antinomias de la razón pura en general" (TschPh, 289). Le parece que el "eterno retorno" "conduce a una comprensión del universo como un juego combinatorio que excluye no sólo la libertad sino precisamente la comprensión de conceptuar el mundo en su esencia como voluntad" (idem). De ello concluye que, en Nietzsche, "el problema del sentido se decidiría en que surge una absoluta ausencia de todo sentido, de cualquier comprensibilidad" (TschPh, 291). Su informe negativo sobre Nietzsche lo concluye con estas sorprendentes palabras:

\footnotetext{
"La llamada de Nietzsche se hace nuevamente válida en que lo terrenal no siempre es conceptuado como mero factum sino como obligación, como algo ante lo que no se han de cerrar los ojos, que no se puede considerar como algo válido, sino como plenificación con la que se vincula paradojalmente un sentido profundo". (TschPh, 293 y ss)
}

El nihilismo actual consiste, por tanto, según Patočka, "en la evidente convicción [...] de que meramente existe un sentido relativo, es decir, rela-

\footnotetext{
7 Vemos que esa opinión de Patočka no difiere esencialmente de la posición que Martin Heidegger desarrolla gradualmente en sus conferencias de los años 1936-46.
} 
tivamente a la vida humana. Porque la vida humana misma [...] permanece inevitablemente precaria, se ha de perturbar cada sentido, y cuando justamente no debía ser perturbado lo será en un tiempo breve" (TschPh, 294). El diagnóstico de Nietzsche conserva su validez. El hombre actual no espera del creador todopoderoso ningún castigo o la eterna felicidad para su alma inmortal. Los postulados de Kant son palabras vacías y con ellas perdió también su categoricidad el imperativo moral. El hombre se erige sobre sí mismo solo. Para disfrazar la pérdida del sentido total, se acoge a un colorista surtido de plenificaciones relativas de sentido en la anónima impersonalidad del "divertisement" pascaliano.

Patočka asiente a este diagnóstico de Nietzsche. Considera como fundamento principal de la crisis nihilista, como ya se ha dicho, el hecho de que Kant reconstruye su teología moral sin enfrentarse al concepto de sentido. Toda la ciencia de los postulados es edificada sobre el concepto de fin. El bien supremo como fin es algo que debe ser alcanzado, alguna realidad futura, y sería también en lo infinito; es algo inexistente, algo óntico. Ya cuando hablamos de Dostoievsi vimos que Patočka busca comprender el sentido de otro modo. El sentido total apareció al perturbado "hombre del subsuelo", según Patočka, como un fenómeno ontológico, como fuente de todo existente que no es ella misma nada existente. En el trasfondo de la reflexión de Patočka sobre el sentido está el dictamen general de Heidegger de que "el sentido sería aquello sobre el fundamento de lo cual algo es comprensible" (KE, 78), expuesto en Ser y tiempo ${ }^{8}$ y citado por Patočka en su ensayo ¿Tiene la historia un sentido? El "sentido como soporte formalexistencial de la apertura que corresponde al comprender ${ }^{\prime \prime}$ no es, claramente, un ente. Pues "el sentido no puede ser derivado, con incuestionable evidencia, del fin y de la finalidad -en nuestra vida surgen los fines sólo desde el comprender reflexivo y de la fijación de aquello que tiene y da sentido" (TschPh, 307). Si es posible podemos salir de la crisis nihilista si dejamos de pensar el sentido en las categorías del fin, si emprendemos una

\footnotetext{
${ }^{8}$ Cfr. M. Heidegger, Sein und Zeit, Tübingen, 1929, p. 151.

${ }^{9}$ Idem.
} 
"revisión de toda la filosofía del sentido de la vida humana, comenzando con Kant" (TschPh, 296).

Esta revisión la lleva a cabo Patočka, como dijimos antes, bajo la orientación de motivos heideggerianos. Él está cierto para sí de que "Heidegger mismo no se ha planteado la pregunta por el sentido [...] en toda su amplitud; él tampoco se ha planteado la pregunta según el sentido parcial o total, relativo o absoluto" (TschPh, 305). ¿Cómo resulta, pues, el proyecto de Patočka?

Ante todo es importante que el hombre no se dé a sí mismo el sentido, como era el caso en la presentación racionalista de los postulados en Kant. Es inevitable que lo encuentre de un modo como justamente Dostoievski lo describe en sus protagonistas como Markel, Sossima o el "hombre ridículo", en el sueño de su propio suicidio. El sentido se tiene que mostrar en una sacudida existencial, "fuera de los límites de aquellas significatividades que son creadas desde el vínculo a la vida humana" (TschPh, 296). Semejante momento del giro lo describe Heidegger en su lección ¿Qué es metafísica? A través de la experiencia de la "nadería" alcanzamos el descubrimiento de la diferencia ontológica, el descubrimiento de la diferencia de ser y ente, en la que el hombre es confrontado con la positividad de aquello que es el ente y es fascinado por la inconmesurabilidad de esta positividad. $Y$ es esta positividad, de la que surge todo sentido, desde el hecho "de que toda significatividad, cada valor, toda meta, finalmente tienen su fundamento en esta comprensión de que 'es', 'hay', 'es claro', 'es presente', en un comprender cuya articulación precede a todo lo que atañe a los cuidados de nuestra propia vida" (TschPh, 298). "El sentido es, sin embargo, una categoría ontológica que originariamente, en su ser originario, es indiferente a los valores, cuidados y fines humanos [...]. El sentido como fundamento de todo comprender es la Proto-Diferencia entre el ser y el ente" (TschPh, 303).

$Y$ de la independencia del hombre llegamos a una amplia característica del sentido total: es ireclamado por algo que no es humano ni una parte o posesión del hombre, en tanto no es ninguna existencia, ningún ente" (TschPh, 304). No puede encontrarlo por ello en la determinación de fines y valores metafísicos, que posiblemente serían a refutar; es un sentido que 
"sale a la luz en el hundimiento, pero él mismo no derrumba, que permanece intocado por la catástrofe del sentido de todo lo real, en tanto él mismo no es real, no es existente" (TschPh, 3000). A este respecto se puede decir de él que sería "absoluto" (cfr., PD III, 81).

Naturalmente, esta absolutez no es nada metafísicamente definido. El sentido total se nos muestra, como escuchamos al principio, de modo histórico. Es siempre de nuevo un fruto de nuestro esfuerzo por elevarnos sobre el sentido relativo, relativamente a la vida humana. La donación de sentido "en la dirección de la vida para la vida" la conceptúa Patočka como el "punto cero de la pretensión histórica humana" (PD III, 456). Él plantea justamente la pregunta siempre en la dicotomía de impulso y caída, donde ese "punto cero" es compuesto con la caída: la vida para la mera vida -esto es el intervalo/plazo de la vida, permanencia en la caída. Contra ese permanecer en la caída se dirige el esfuerzo de liberarse de ella, y eso es el impulso. Este impulso es acompañado por la pretensión de una "vida en verdad" (idem). Pero la verdad no es aquí comprendida como adecuación o como algo místico que sería indiferente conocer con un desprendimiento del torbellino de la vida y del mundo, sino como algo así como la verdad heideggeriana del ser, como el históricamente cambiante abanico de un ámbito abierto en el que se nos muestran los entes y tiene lugar la fenomenologización. El esfuerzo por una vida en verdad significa para Patočka, entonces, la pretensión de establecerse siempre de nuevo en ese ámbito abierto, hacerlo siempre nuevamente fenómeno, descubrir de qué forma nos aparecen los entes. Esto tiene que ser siempre nuevamente realizado porque también aquí, en el ámbito del fenómeno ontológico, se hace valer el principio de la finitud del modo humano de ser, o en su caso del ser en general. También es aquí que se oculta algo esencial en el descubrir: "Es un descubrir que con lo que lleva al aparecer y lo que es liberado, a la vez no menos algo esencial oculta; el descubrir no es pensable sin este encubrir que está vinculado inseparablemente con el fenómeno" (PD III, 455). La estructura del aparecer, que consiste en los fenómenos ontológicos en que se oculta tras el fenómeno que se muestra lo que aparecer lleva, necesita siempre de nuevo, por tanto, ese esfuerzo descubridor. La estructura del aparecer -0 , 
como Patočka dice, el fenómeno- es, por ello, un "momento fundamental de la historia", aquel fuelle/resorte que contiene la historia en curso. La historia es, por tanto, la historia de nuestro esfuerzo descubridor en torno a fenómenos ontológicos que permanentemente de nuevo emergen desde el ocultamiento. Descubrir los fenómenos ontológicos, pero a la vez ser remitidos a ellos, a que y como ellos mismos emergen y se nos muestran, significa el intento de comprender ese descubrir, conceptuar en lo que somos con ese descubrir.

Por ello, los fenómenos ontológicos no intentábamos penetrarlos, porque queríamos comprender cómo se nos muestra lo ente, por tanto, por ello, porque nosotros queríamos comprender los fenómenos ónticos. Queríamos conceptuar por qué a nosotros el ente justamente aparece así como nos aparece en un tiempo dado, y no de otro modo, por ejemplo, así como aparece en otro tiempo, o como nosotros quisiéramos que debía aparecer. Y aquí comienza la comprensión de Patočka a apartarse, naturalmente, en lo esencial, de Heidegger. Mientras que Heidegger propone esperar la gracia del ser en recogida profundidad en las formaciones históricas del fenómeno ontológico y prepararse hasta que se muestre en cierta forma de otro modo el ser como en la indigente constelación de la "esrtuctura de emplazamiento" (Gestell), Patočka quiere vincular del descubrimiento de los fenómenos ontológicos directamente con el actuar histórico: si podemos conceptuar el fenómeno ontológico, si podemos conceptuar por qué se nos muestran los fenómenos ónticos, es decir, lo ente, como se muestran, podemos, tenemos que actuar - si no queremos caer en una cansada decadencia ni vivir el mero tiempo de vida de acuerdo con nuestro descubrimiento.

Pero, a pesar de su "absolutez", el sentido que se nos da así en el descubrir del fenómeno ontológico es un sentido cuestionable. Por una parte es problemático, porque nunca podemos estar seguros de si nos hemos abierto al descubrimiento de la "verdad del ser" objetivamente de modo que pudiera mostrarse el ser mismo como quería; no podemos estar seguros de si dejaríamos que apareciese él mismo y de si no hemos infiltrado en su aparecer nuestros añadidos "subjetivos", con los que lo truncamos; no podemos estar seguros "de si somos capaces de conceptuar su disimulación co- 
mo misteriosa presencia de un ámbito inconmensurable o si queremos arrancarle algo de su donación, de su mensaje, con el fin de elevarnos a nosotros mismos a ser los señores de nuestro mundo circundante" (TschPh, 303). Por otra parte es problemático porque -como vimos- aparece como un "fruto de la oscuridad que extiende de modo invencible al fundamento propio de todo" (PD III, 81 Anm. a).

Por tanto, la historia es un proceso de descubrimiento del sentido que, sin embargo, "tiene su forma problemática, de ningún modo el carácter de un camino seguro en el que se avance sin esfuerzo" (PD III, 455). Es éste un camino sobre el que el hombre tiene que soportar "una permanente sacudida de la conciencia ingenua de una plenitud de sentido" (PD III, 69) sobre la que "no puede cerrar los ojos ante la oscuridad, la cuestionabilidad, la contradicción" (PD III, 81 Obs. a). Con ello se tiene que conceptualizar que somos agraciados "por medio de una inalterable donación que no es comparable con nada relativo" (TschPh). Dice Patočka que "el hombre se encuentra ante una tarea inmensa: no reclamar el sentido para sí, no elevar la pretensión de una plenitud de sentido del universo a su propio provecho sino, por el contrario, conceptuarse a sí mismo como un ser que existe desde el sentido para el sentido, que vive para que surja un mundo pleno de sentido, que se da para que el sentido cuyo fundamento "está" fuera del ente, se asiente en él y se acreciente" (TschPh, 308).

De lo dicho se hace claro que lo principal de lo que trata Patočka en la búsqueda del sentido es su totalidad o, como dice a veces casi disculpándose, su "absolutez". Para ello parte de un punto de vista que comparte con Wolfgang Weischedel ${ }^{10}$, "de que el sentido parcial y condicionado pende del total e incondicionado, de que fenomenalmente le precede" (PD III, 65 Obs. a). "Cada sentido singular indica un sentido total, cada sentido relativo indica uno absoluto" (KE, 83). Su pregunta es: ¿es posible pensar a partir de Kant y Nietzsche un sentido omniabarcativo o absoluto?

Parece, a primera vista, que la equiparación de ese sentido total con el nivel ontológico era ya una respuesta satisfactoria a esa pregunta, porque

${ }^{10}$ W. Weischedel, Der Gott der Philosophen, vol. 2, 1971, pp. 165-182. 
con ello se mostraba tanto una totalidad como también una cierta absolutez del sentido de la vida y de la historia. En el concepto de interrogabilidad del sentido total fue indicado un entendimiento para historicidad de ese sentido y la inevitabilidad de la actividad humana en la historia. Sin embargo, yo pienso que aquí radica una cierta dificultad, que conecta con el central punto de partida de toda la concepción, justamente con la solicitud por una totalidad o, en su caso, absolutez del sentido. Si el sentido omniabarcante es identificado con la fuente de luz en la que se muestran las cosas, si es equiparado con la "verdad originaria" como fuente de la verdad y no-verdad, de los errores y decepciones, a la vez también es la fuente del sentido y del sinsentido.

Evidentemente se trata aquí de un sentido relativo y de un sinsentido relativo, es decir, relacionado con la situación humana de la acción. De completamente igual si en el marco de la teología moral kantiana o si en el marco de un actuar histórico que se apoya "sobre una inalterable donación que no es comparable con nada relativo" (TschPh, 308) -en ambos casos se tiene que decidir el hombre actuante sobre el fundamento de su facultad de juzgar, y esta decisión tiene inevitablemente un carácter hermenéutico. Mientras el imperativo categórico en la teología moral kantiana tenía un poder de veto y así sobrepasaba, de modo absoluto, la situación hermenéutica de la acción, no disponemos en nuestra actual situación de nada parecido. Cada "verdad originaria", el hecho, como $-y$, ante todo- el que se nos abra una situación, es justamente constitutivo para nuestro entendimiento de una situación, pero desde el sinsentido de una situación en la que somos quizás maduros, no nos ayuda. La explícitamente declarada interrogabilidad del sentido total y del conflicto en el ser no pertenecen propiamente a un nivel ontológico, sino que eso es en conjunto una inevitable característica del sentido como tal: con ello el sentido puede ser, en general, sentido, tiene que ser perturbable, extraviable, tiene que ser siempre nuevamente enderezable y dirigido contra una determinada forma del sinsentido ${ }^{11}$. $117 \mathrm{~s}$.

${ }^{11}$ Cfr. Pavel Kouba, Die Welt nach Nietzsche, München, Wilhelm Fink Verlag, 2001, pp. 
Pero el "sentido total" de Patočka debía llevar fuera de esta situacionalidad. En su no ser existente es indestructible y es expresamente puesto en una contradicción contra la precaria finitud de la existencia humana. Se debe mostrar en el mismo encontrarse fundamental existencial de la angustia, en la que somos confrontados "con la posibilidad última, más exterior, insuperable e inintercambiable de la incontrovertible No-existencia" (TschPh, 299). Como si la apariencia del "sentido total" ya debiera desvanecer u ocultar en el germen el sinsentido de la muerte, que, sin embargo, presta al ser finito, mortal, su dignidad. La supraordenación del "sentido total" sobre el sinsentido relativo de la situación conduce justamente, en fin, de modo parecido a como ocurre en la ontoteología metafísica, a la nivelación de la diferencia situacional entre sentido (relativo) y sinsentido (relativo). Con ello penetramos en la situación de una decisión entre un "sentido" abarcativo, absoluto (ontológico, no-objetivo e inconmovible), de una parte, y las formas meramente ónticas y cambiantes del sentido y del sinsentido, de otra parte.

Pero se tiene que preguntar si con ello no se oculta nuevamente lo precario de un posible sinsentido, es decir, aquella determinación fundamental existencial sin la que la estructura temporal de nuestro ser extendido entre pasado y futuro justamente no sería posible - de un pasado que ya no es modificable y da a nuestro presente un sentido irrefutable y un futuro que justamente es incierto pero que permite proyectar otro sentido, al que podríamos ofrecer nuestro presente. Pensar el conflicto en el ser con Patočka significaría, pues, pensar una acción situacional - una acción en la que se trata de si un sentido es mantenido o es perdido-, una acción que no sería "meramente relativa", sino acaecida en dramática seriedad, cuya forma objetivamente es ontológica. 